\title{
EL HOSPITAL INFANTIL UNIVERSITARIO DE SAN JOSÉ Y LA FUNDACIÓN UNIVERSI- TARIA DE CIENCIAS DE LA SALUD (FUCS)
}

\author{
Roberto Jaramillo Uricoechea MD*
}

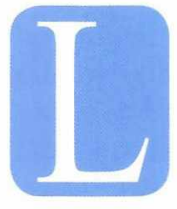

a misión de la FUCS se define como una institución de educación superior que asume con responsabilidad la formación integral de sus estudiantes en los campos de la ciencia, la investigación y la tecnología con fundamentos de excelencia científica, sentido ético, moral, humanístico y de proyección social con el fin de permitir el análisis objetivo y racional de los problemas de la comunidad y contribuir a mejorar su calidad de vida.

Como visión se tiene que será una universidad reconocida por la calidad de sus egresados, la excelencia académica e investigativa, con alianzas estratégicas nacionales e internacionales y apoyadas en una infraestructura y cultura organizativa universitaria, con los debidos soportes administrativos y financieros que le permita cumplir con sus objetivos institucionales.

Es por esto que la compra del antiguo Hospital Infantil Universitario "Lorencita Villegas de Santos" en liquidación, se ha constituido en el proyecto estratégico más importante para el crecimiento de nuestra institución, la FUCS, en los próximos años, pues esto nos permite el desarrollo en todos los frentes.

El ampliar los campos de práctica no se escapa a nadie que es un logro de gran importancia, pues con el crecimiento y desarrollo de nuevas facultades de ciencias de la salud, cada día es más difícil la enseñanza, son menores las oportunidades de conseguir campos de práctica y los convenios docen-

\footnotetext{
Rector, Fundación Universitaria de Ciencias de la Salud.
}

cia-servicio indispensables para lograr los objetivos propuestos son cada vez más costosos.

Con la compra del Hospital Infantil Universitario de San José y junto con el Hospital de San José, quedamos como la institución universitaria con dos hospitales propios para las prácticas de nuestros estudiantes de medicina, enfermería, instrumentación quirúrgica y citohistología.

El hecho de tener más centros de práctica nos permitirá incrementar los convenios docencia-servicio y aumentar la productividad en todo sentido. De la misma manera nos permitirá crecer como centro docente y poder cumplir con el propósito de nuestra visión, para convertirnos en universidad.

Pero además del aspecto académico, es necesario que consideremos el beneficio que representa para la FUCS tener un campus universitario en el norte de la ciudad, con áreas deportivas y ambiente fresco por los árboles que rodean las edificaciones y los prados que lo circundan.

Aunque el centro hospitalario está en remodelación, esperamos que muy pronto podamos iniciar actividades docente asistenciales en urgencias, consulta externa y progresivamente en el resto del Hospital, para beneficio de nuestros pacientes y por supuesto, de nuestros estudiantes.

Las actividades puramente docentes ya las hemos iniciado desde enero del presente año, pues gracias a la remodelación del edificio del auditorio con capacidad de 223 sillas y dos aulas, una para 60 estudiantes y otra más pequeña donde funciona 
el centro de cómputo, han realizado sus clases los alumnos de preuniversitario y los de I semestre académico de medicina.

También se vienen desarrollando diplomados y conferencias de extensión como el de "Docencia universitaria en ciencias de la salud" y conferencias para padres de familia y para rectores y psicólogos de algunos de los establecimientos de educación secundaria de la ciudad, tratando temas de interés general para los educadores como la drogadicción, la planificación familiar, etc.

Todos estos aspectos nos dicen con claridad que los beneficios para la universidad, los docentes y los alumnos son inmensos. Esta sede nos va a permitir crecer y como dice nuestra visión "realizar alianzas estratégicas nacionales e internacionales", ahora que viene el tratado de libre comercio y la globalización en todas las actividades de nuestro entorno.

El esfuerzo ha sido muy grande, las dificultades también, pero hay que reconocer que este logro ha sido de mucha gente, liderada por nuestro presidente del Consejo Superior el profesor doctor Jorge Gómez Cusnir.

Se ha encomendado poner a punto el Hospital en todos los aspectos docente asistenciales a la profesora doctora Laima Didziulis G. y con ella, trabajando hombro a hombro estamos constituyendo la que ya no es una ilusión sino una realidad: revivir un hospital cerrado hace siete años, para beneficio de nuestros enfermos y toda nuestra comunidad universitaria.

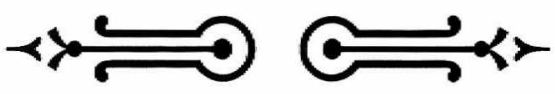

